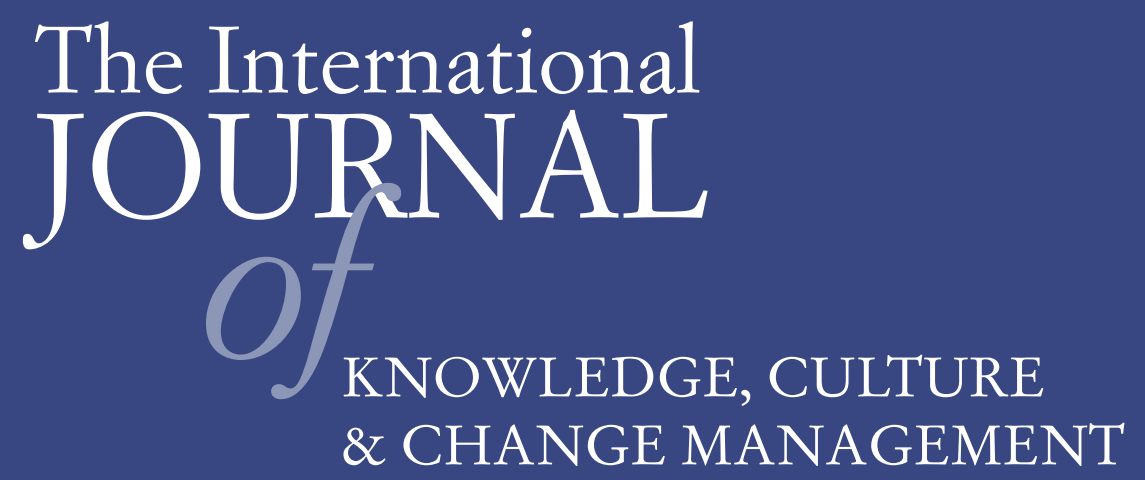

Volume 8, Number 5

A Knowledge Management Perspective on Business Models

Rozeia Mustafa and Hannes Werthner 
THE INTERNATIONAL JOURNAL OF KNOWLEDGE, CULTURE AND CHANGE MANAGEMENT http://www.Management-Journal.com

First published in 2008 in Melbourne, Australia by Common Ground Publishing Pty Ltd www.CommonGroundPublishing.com.

(C) 2008 (individual papers), the author(s)

(C) 2008 (selection and editorial matter) Common Ground

Authors are responsible for the accuracy of citations, quotations, diagrams, tables and maps.

All rights reserved. Apart from fair use for the purposes of study, research, criticism or review as permitted under the Copyright Act (Australia), no part of this work may be reproduced without written permission from the publisher. For permissions and other inquiries, please contact <cg-support@commongroundpublishing.com>.

ISSN: $1447-9524$

Publisher Site: http://www.Management-Journal.com

THE INTERNATIONAL JOURNAL OF KNOWLEDGE, CULTURE AND CHANGE MANAGEMENT is a peer refereed journal. Full papers submitted for publication are refereed by Associate Editors through anonymous referee processes.

Typeset in Common Ground Markup Language using CGCreator multichannel typesetting system http://www.CommonGroundSoftware.com. 


\title{
A Knowledge Management Perspective on Business Models
}

\author{
Rozeia Mustafa, Vienna University of Technology, AUSTRIA \\ Hannes Werthner, Vienna University of Technology, AUSTRIA
}

\begin{abstract}
So far no theory has been reported academically on the expected relationship between Business Models and Knowledge Management. The theme of this paper is to look into domains of Knowledge Management and Business Models simultaneously and find missing links of a probable relationship between two domains. In order to establish this connection, we can work in the domains of Organizational Transformation (Business Re-engineering), Knowledge management and Business Model concepts. It may help establish a link on theoretical basis. For this purpose, first we will propose a modified definition of Business Model and then discuss a hierarchical structure of knowledge related functions referred as 'Knowledge Repository'. We will also probe where knowledge, as a strategic asset, is located in an organization which is then shared among interacting partners in a value chain. We will also link this phenomenon of Business Model concept with so called 'Open Business Models'. The adapted term 'Open Business Model', referred by Chesbrough (2006), will be used in a context of creating value and to capture part of this value during transformation process. In this paper, we will initiate debate on two hypotheses, 1) knowledge related functions are core elements to effectively manage knowledge and, 2) Business Model has a direct causal relation with Knowledge Management. This multi-theory research may lead towards building a theory of 'Open Business Models' in the domain of E-Commerce which intends to fill a gap between Knowledge Management and Business Models, otherwise an untested area so far in the field of E-Commerce. This research will also provide new venues for research in the field of Business Models and Knowledge Management.
\end{abstract}

Keywords: Business Model, Knowledge Repository, Knowledge Management, Open Business Models

\section{Introduction}

$\mathrm{T}$

HE DISCUSSION OF business models was started in late 1990s when the dotcom bubble was about to mature. It was a common understanding that internet would make existing businesses or even the economic theories obsolete (Osterwalder, 2004) and there would be a new array of theories and concepts related to internet business. The academic research in the field of business model concepts is developing and a myriad of concepts, definitions, ontologies and frameworks have been added since that time. But still there is a lack of a proper theory for business models concept as reported by Lambert (2006). She has provided a schematic framework of progression of research in the field of business models in a period from 1998 to 2007. The term business model was first explained by Paul Timmers in late 90's as a pure business concept explaining the logic of doing business for a firm (Pateli and Giaglis, 2004). According to Timmers (1998), 'a business model can be defined as architecture for the product, service and information flows, including a description of various business actors and their roles and a description of potential benefits for various business actors and a description of sources of revenues'. Timmers reviewed the terminology in the context of B2B scenarios, and therefore, it established the concept of inter-networking among various actors in a value chain and flow of information, products and services to leverage potential benefits. Later various authors defined the business model concept in the context of different characteristics e.g. Weill and Vitale (2001) have explained business model as a tool for relationship among actors; Linder and Cantrell (2000) described change in business models; Gordijn and Akkermans (2002) offered the concept of the e3 value model; Osterwalder, et al (2005) propagated a business model ontology, depicting relationships and dependencies of business elements in the framework of balance score card; and Tapscott (2006) worked on business model concepts with flexible boundaries in collaborating environments and business webs.

In this paper, we will initiate a debate on two assumptions: 1) knowledge related functions are core elements to effectively manage knowledge: and 2) a business model concept has a direct causal relation with knowledge management. This multi-theory debate intends to lead the phenomenon of business model to the notion of 'Open Business Model'. Since knowledge management could have a potential relation with the business model concept, we further intend to fill a theoretical gap between two domains, which is otherwise an untested area so far in the field of E-Commerce. The paper is divided into two parts; the first part consists of a proposed modified definition of business models, describing some of

THE INTERNATIONAL JOURNAL OF KNOWLEDGE, CULTURE AND CHANGE MANAGEMENT, VOLUME 8, NUMBER 5, 2008

http://www Management-Journal com, ISSN 1447-9524

(C) Common Ground, Rozeia Mustafa, Hannes Werthner, All Rights Reserved, Permissions: cg-support@commongroundpublishing.com 

VOLUME 8

the main characteristics of business model with a historical overview of this concept, whereas the second part explains the need to define knowledge related functions, for which we will use the term 'Knowledge Repository'. The term 'knowledge repository' is normally used by Artificial Intelligence (AI) experts. We will try to generalize this terminology in a business organization domain. At the end, we will conclude our paper with potential benefits and future directions to be established by the current research in the domain of business models and knowledge management.

\section{A Unified Approach to the Concept of a Business Model}

Substantial research has been going on in the field of business models. However the field is relatively young and no unified theory has yet emerged as reported by Lambart (2006). Various attempts have been made resulting in myriads of conceptualizations in the context of specific problem solving domains (Porter, 2001; Lambert, 2006). In this paper, we will try to establish a link between business model concept and knowledge management, a probable relationship, which needs to be explored in order to reach some common grounds to build a theory for business models. Initially we can see two main tracks of defining business models, the one with a simple definition of doing business and the second with conceptualization of a framework to reduce complexity to an understandable level (Osterwalder et al., 2005). First we offer a modified definition of the business model concept based on various characteristics and then will discuss the need to propose this modified definition. However it is important to mention here that our modified definition is primarily based on the Timmers definition.

"A business model is an articulate structure for sharing products, services, resources, assets and knowledge flow among interacting partners (including external and internal customers, consumers, competitors and the environment) in order to exchange potential benefits from specific resources of revenue with the capability of flexible boundaries".

This definition provides a unified approach towards defining a business model concept keeping in view three important characteristics of an organization i.e. 1) an articulated structure for creating value, 2) the exchange of value and 3) the capability of change. The motivation to propose a modified definition emerged due to lack of availability of these characteristics in a single definition. The above definition suggests that business models should have an architecture for sharing flow of product, service and knowledge among participating actors, describing various business actors and their role as explained by Timmers (1998). A business model concept should provide a framework for interaction between these business actors including customers, consumers, stakeholders, suppliers and competitors as propagated by Weill and Vitale (2001) in their definition. The business model concept should also have the capability of changing the route of flow of products, knowledge and resources with the passage of time due to factors like business strategies, environmental forces, customers' requirements, consumers' preferences and competitors. Such business models should quickly respond to environmental stimuli created by changes in the environment through flexible boundaries. The mechanism of this response can be developed by leveraging new innovative ideas (Tapscott, 2006). The response is strategically developed by the organization like strategic alliances, partnerships, mergers $\&$ acquisitions, spinoffs etc. The business model should also utilize key assets, resources, information (present not only in the company's own business but also in other companies' businesses (Chesbrough, 2006)) and position of the company in a value chain.

\section{Articulated Structure}

Our proposed definition suggests that a business model is a conceptual model, i.e. a formal description with a specific structure to create value proposition, identify a market segment and define the structure of the value chain. It provides a framework to support the implementation of strategies. This framework also provides opportunities for an organization to shape its strategies and create core competencies. Some researchers like Gordijn and Akkermans (2002) have emphasized this characteristic of business models in order to specify value exchange process and add effects of visibility which helps participants to manipulate their business models visually.

\section{Capability of Interaction with Other Businesses}

The conceptual structure of a business model may help to identify the process of value exchange among interacting partners. The conceptual structure may also identify which partner receives what value as in case of the e3 Value model (Gordijn and Akkermans, 2002). Since the business model concept has been used as a tool for identifying the relationship among partners (Weill and Vitale, 2001) in a value chain, this relationship should be developed by interaction among partners. This interaction then facilitates the flow of value (and knowledge) inside and outside of an organization (Chesbrough, 2006). Later on, we will discuss that knowledge is a primary resource underlying the value creation process. It may lead us to assume that the business model concept can provide a potential link with the knowledge 
management domain as knowledge generation is an essential knowledge management activity (Davenport and Prusak, 2000)

\section{Capability to Change}

Another characteristic is the capability of changing boundaries, i.e. its navigational property which helps managers to steer their business in uncertain conditions for future viability. A business model describes the pattern of interaction and scalability properties (Tapscott, 2006). Since an organization shares the value and the knowledge in a value chain, it can change the pattern of interaction with partners and can establish virtual structure (scalability) in order to maximize benefits of value and knowledge. Outsourcing and offshore strategies are best employed with the aid of this characteristic.

\section{Knowledge Related Functions}

One objective of this paper is to conceptualize the knowledge related functions into some kind of hierarchical structure which may provide a logical basis of sharing and understanding the creation and flow of knowledge among interacting participants in an economic exchange process. As we have already proposed a modified definition of a business model, we will now propose another conceptual framework for linking the concept of business model with knowledge management. The purpose of this discussion is to create a conceptual hierarchy of knowledge based functions being performed in any organization. Since each organization is comprised of its own specific functions and processes, this conceptual hierarchy will help us to assume that each organization is comprised of various knowledge related functions, a function being the result of a process of value creation.

\section{Conceptual Decomposition of Organization into Processes and Activities}

Business models are established on the foundations of strategic planning and business processes which help managers to formulate strategies to achieve competitive advantage over the rivals (Chesbrough and Rosenbloom, 2002). In the last two decades of $20^{\text {th }}$ Century, the concept of a knowledge based view of the firm has proved attractive to the strategy and knowledge experts as an alternate to the product based view or competitive advantage of the firm (Sveiby, 2001).

The knowledge based view of the firm provides validated perspectives to analyze the firm in terms of integrated processes for superior firm performance (Emery, 2002). We can decompose an organization up to an atomic level of activity conceptually. This conceptual decomposition disintegrates processes and functions into activities and tasks which help to identify the source of knowledge located within an organization. According to this decomposition, organizations define themselves into different departments such as purchasing, product development etc. These departments are responsible for a specific business function. A business function is performed by group of logically connected tasks performed together in some logical sequence to accomplish an objective or deliver a business product (Morgan Madison Vocabulary, 2008). A function can also be defined as a group of related activities and/or projects for which an organizational unit is responsible, that is part of process or often known as a sub-process within a process (Bureau of Justice Assistance Glossary, 2008). Organizations often divide themselves into functional units, such as purchasing, product development, order fulfilment etc. (U.S Gov. Accountability Office Glossary, 2008). Therefore, each function of an organisation may be broken down into a number of 'activities', which are part of a single process or sub-processes of different processes. The following diagram represents the conceptual decomposition of an organization up to process level. 


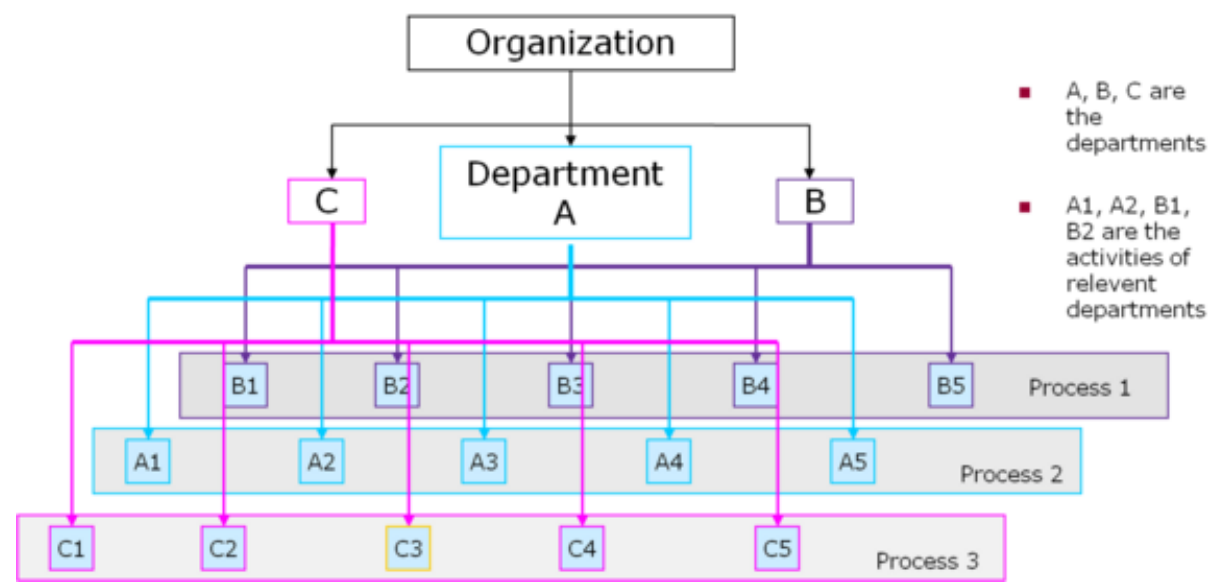

Figure1: Decomposition of Processes and Functions in an Organization

Figure 1 represents the composition of an organization's departments up to the level of processes which create value. The processes are composed of value creating activities, either performed by man or machine or both. These activities are building blocks of a process which incorporates specific information about that process. This information is further extended into knowledge by a combination of framed experiences of human being, values, contextual information (of specific process) and expert insight providing a framework for evaluating and incorporating new experiences and information'(Samaddar and Priestley, 2005).

The definition of function suggests that it is a set of related activities and we also explain that activities are building blocks of a process, thus we can propose that organizations are composed of functions based upon value creation processes. Since knowledge is the 'primary resource underlying new value creation' (Felin and Herstely, 2007), this may lead us to propose that these functions are related to knowledge. Let's illustrate this proposition with the help of an example. As we have already discussed how organizations often divide themselves into functional units, we will take an example of a product development department. This department is responsible for developing a new product which is its main function in the light of the definition provided on the internet (www.wordnet.princeton.edu). The process of new product development is composed of various subprocesses and activities. We list down some of the sub-processes for new product development process and explain a relationship between interdepartmental processes and their functions during this process. The new product development process includes subprocesses like:

Sub-process 1: Allocation for funds for new product development

Sub-process 2: Design product

Sub-process 3: Prototype testing

Sub-process 4: Production of new product

Sub-process 5: Launch new product in the market

In order to explain the relationship of process and function, let us review the example of prototype testing graphically. 


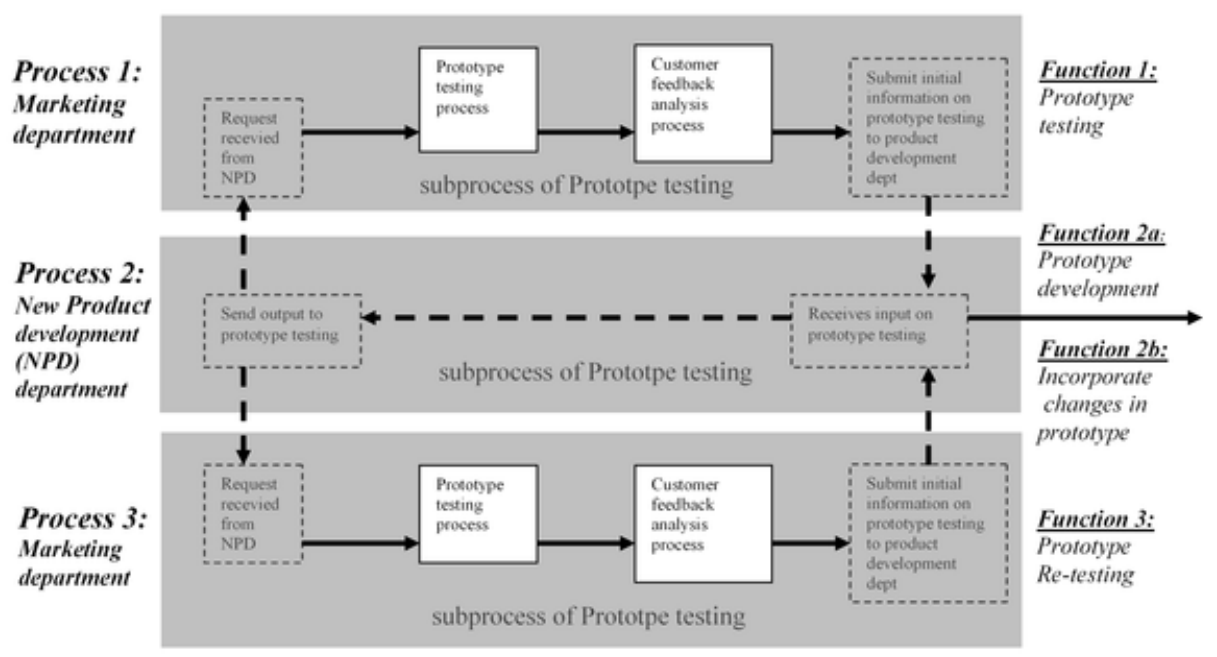

Figure 2: Flow of Activities and Sub-processes between Marketing and Product Development Department

The solid lines in Figure 2 represent processes, subprocesses and their flow/connectivity, whereas the broken lines show specific activities or their flow within or in between sub-processes. New product development department is a functional unit of a manufacturing organization to perform various functions during new product development process. These functions are performed by developing new products according to customers' requirements.

A new product development process is composed of various activities and sub-processes like:

- Information received from the finance department about availability of financial resources for new product development,

- Sending a request to the design department for developing new designs,

- Forwarding information to the marketing department to test the prototype of new product,

- Receiving input from the marketing department about results of prototype testing,

- Forwarding newly developed product samples to the production department for manufacturing.

We can observe that most of these activities are associated with the exchange of knowledge within different departments of this manufacturing organization. For example, the product development department receives input from marketing department on prototype testing. In the light of the information received from the marketing department, product development department adjusts the prototype according to revised customers' preferences and requirements, analysed during prototype testing. These revised customer preferences and requirements were analysed by the marketing department during the prototype testing process. Now the function of the product development department is to incorporate these requirements into existing prototype. This initiates another sub-process of developing a new prototype which is further tested and confirmed from selected group of customers. In this way, the function of the product development department is modified as new knowledge is received from the marketing department (source) to perform a new set of activities. This shows us that the function can be modified or changed by addition of new knowledge from different resources. Therefore, we can suggest that a function is a set of elements which has a direct relationship with knowledge. In the above example, function of 'Prototype Development' is composed of connected activities and sub-processes of marketing and product development department. This function can be modified into 'incorporate changes in the prototype' if new knowledge is added from another source (marketing department in this case). If no new knowledge was received on prototype testing by the new product development (NPD) department, its function of prototype development will continue till sub-process 3 is completed. Now the focus of activities will be shifted to the next subprocess 4 , i.e. production of new product.

The above example shows that a function can be part of different processes or sub-processes (when activities of different organizational departments are connected) in order to achieve the objective. Since the main objective of an organization is value creation, the function then can be assumed as part of value creation process. As we know that knowledge is the primary resource underlying value creation process, we can assume that knowledge has a direct relationship with function (Felin and Herstely, 2007).

Since processes are key to innovation in terms of business engineering (Österle, 1995), therefore, this conceptual model of knowledge related functions 
can help us to understand organizational development processes in terms of knowledge.

\section{Brief Literature Review for the Term 'Knowledge Repository'}

The term 'knowledge repository' has been used in the recent literature for sometime, particularly in the field of 'Artificial Intelligence'. Liebowitz and Beckman (1998) have defined Knowledge repository as an "on-line computer-based store house of expertise, knowledge, experiences, and documentation about a particular domain of expertise. In creating a knowledge repository, knowledge is collected, summarized, and integrated across sources". Dingsøyr \& Røyrvik (2003) have explained this term as "Experience bases" or "Corporate Memories".

Rowley (2000) has well expressed the concept of 'knowledge repositories' in the form of documented, explicit knowledge contained by academic institutes or universities and availability of this knowledge to associated business firms. She also raised the question of using the terminology 'repository' for such institutes. She propagated that these universities participate in the wider knowledge creation process which leads to the creation of knowledge repositories that foster the future generation research by researchers. Since these higher education institutes are sometimes funded or strengthened by big companies to accelerate research and innovation in their particular field of interest (Chesbrough, 2006), these knowledge repositories have strong links with these organizations which impart a very important role in knowledge creation and transfer. This term is analogous to the 'organizational memory' but wider in its scope, as it covers all the organizational components from information systems to its employees. Organizational memories (OM) have the properties of learning, remembering and talking based on the domain of sociological as well as psychological perspectives (Bannon and Kuutti, 1996). These organizational memories are conceptualized on the basis of human computer interaction and 'cooperative work' for the computer supported cooperative work community. OM is a concept discussing the procedures how organizations use and maintain knowledge in various forms.

\section{Definition of Knowledge Repository}

Based on the above explanation of knowledge related functions and literature review, we will now propose a modified definition of knowledge repository:

"The knowledge repository can be defined as a site (physical or virtual e.g. a domain on the world wide web), location (knowledge store like library, document storage room), computer, an entity or an organization to store, reside or locate knowledge for its reuse or redistribution over a network of actors (involved in exchange of knowledge) through different channels".

As the definition suggests, an organization could be assumed as a storage house for knowledge, as a strategic asset with the particular emphasis on creation, learning and distribution over a wide network of actors participating in value creation processes. Knowledge is the term used for aggregate bits of information or data 'further extended into knowledge by a combination of framed experiences of human beings, values, contextual information (of specific process) and expert insight providing a framework for evaluating and incorporating new experiences and information' (Samaddar and Priestley, 2005). Therefore, we may infer that it could be any kind of knowledge like tacit \& explicit (Polanyi, 1966), (what), procedural (how) or causal (why) (Zack, 1999) or general (in broad context) or specific (in narrow context) (Gallupe, 2001). Similarly, taking repository in general terms, it should not be limited only to hardware like servers, computers and networks. According to the basic definition, anything which stores some kind of knowledge can be termed as a knowledge repository, from a server to a human being to an organization.

Therefore, the term may be used at micro level with only one repository to store a single type of knowledge or at macro level i.e. in terms of organization which may be assumed mega-repositories with a combination of various sub-repositories in the form of computers, hardware, servers, networks and the employees. A simple example of knowledge repository could be a single cell as it contained all of its functional information in the form of genes located centrally in its nucleus. Similarly, a human being may also be an analogue to a knowledge repository on account of his/her unique intelligence and excellently developed memory cells to retain knowledge (tacit) for a long time. A combination of hardware and software specifically designed to store knowledge and information is a very common example in database management. Similarly if we observe the basic definition of knowledge repository, an organization or a firm can also be termed as knowledge repository due to its characteristics of a combination of hardware, software, networks and employees retaining all kind of knowledge.

\section{Hierarchical Structure of Knowledge Repository}

In figure 3 the proposed model of a knowledge repository depicts three layers, namely the strategic layer, the business model layer and the business process model layer (see figure 3). Each layer is composed 
of different knowledge related functions conceptually performed by the organizations. The knowledge related functions are stacked together in a hierarchical level, showing the order of granularity and scope.
Functions of wider scope with number of connected processes are grouped within the strategic layer; where as functions composed of single processes are grouped at business process model layer.

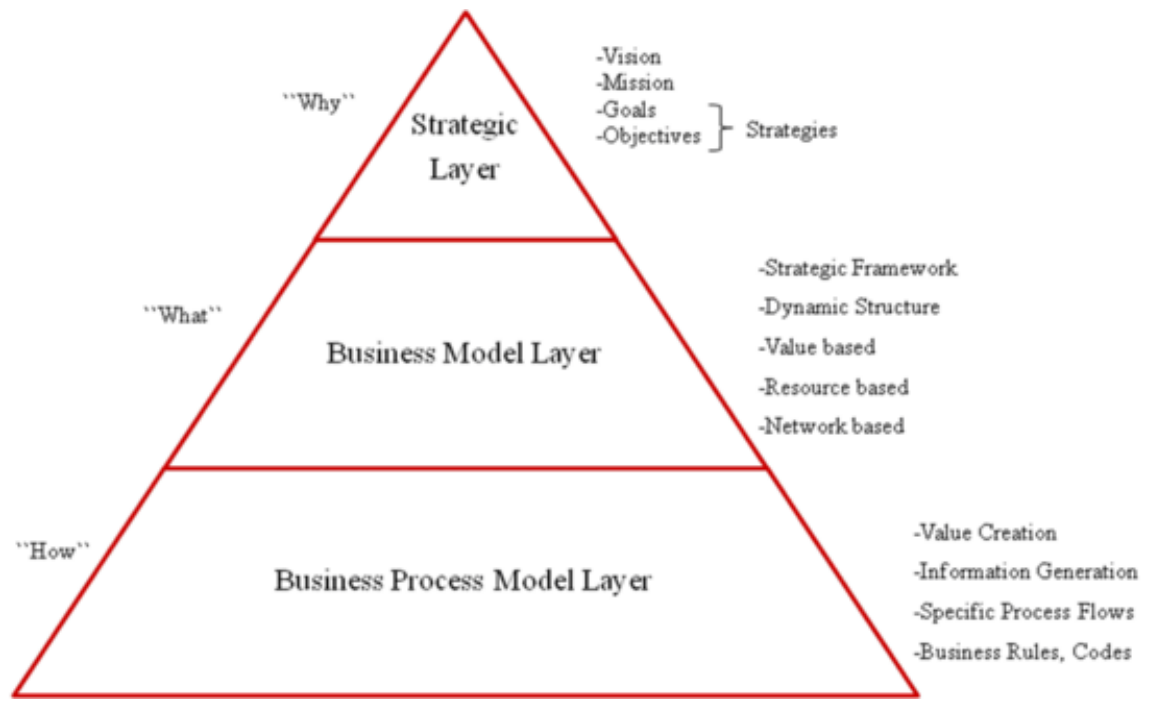

Figure 3: Hierarchical Structure of Knowledge Repository

\section{Strategic Layer}

The top layer consists of strategic planning including vision, mission, goals and objectives. This layer involves 'strategic planning' and 'directing' functions of management. The organization defines its strategy, sets directions and makes decisions to allocate resources to pursue the strategy. Strategy is the plan of top management to attain outcomes consistent with the company's 'goals \& objectives (mission).' Strategy is a prediction about what the market, customer and competitors 'will do' in future and how that will change depending upon the 'actions' a company takes. Strategy is a steering guideline to transform 'goals' and 'objectives' into 'actions (results)'. Strategy has particular characteristics of an 'if-then' (condition-consequences) nature; therefore it can be 'redesigned' if objectives are not achieved. This layer approaches the problem with the connotation of 'WHY'. For example, in the above example of a manufacturing organization, it is decided that consumers should be included in the new product development process. For this purpose, a marketing department will contact a pre-selected group of consumers who will participate in the prototype testing process. Since participation of consumers in a new product development process is a strategic decision and heads of different departments of organization are responsible to evaluate this decision, the function of evaluating this decision can be categorized in the strategic layer of knowledge repository. This evaluation process will be composed of inputs and knowledge received from connected activities and sub- processes from different departments of the organization.

\section{Business Model Layer}

The middle layer of knowledge repository is the business model layer. This layer acts like a bridge to match up the strategic planning with business processes. This is the layer which provides a framework for aligning business processes with organizational vision, mission and strategies. The business model framework, as described in general, is a translation of strategies into actions to achieve specific objectives and goals. Business models address the specific problem in the connotation of 'WHAT'. Business models are the dynamic frameworks which provide support for the strategic implementation of vision and mission of the organization. The dynamic nature of this framework provides opportunities to re-design strategies at strategic layer. Business models are based on value, resources or networks; depending upon the nature of the organization, its value chain, the market it serves and target customers. As described previously, business models provide a conceptual framework to an organization to support its business processes. Continuing with the previous example of a manufacturing organization, the organization develops new products at its own premises. This function is the core competency of this manufacturing organization. However, external customers are included in this process for prototype testing in order to incorporate true needs of the target consumers. The framework which provides opportunity to a group of consumers to be a part of the new product development process is conceptually 
being provided by the business model. If the organization decides that it will test its prototype in house without a group of target consumer representatives, then the conceptual framework of this organization will be different and the group of consumers will not participate in the organizations processes. This decision is facilitated by the inputs from the marketing department and the product development department. This shows that the business model layer provides a framework to translate strategies into actions in order to create value.

\section{Business Process Layer}

The lowest layer constitutes the basic business processes. This layer specifically deals with the creation of generic value which is then further modified with value added by upper two layers. This layer addresses the problem in the connotation of 'HOW'. All the basic technical and technological processes of an organization could be categorized at this layer. It includes specific process flow, business rules, product design patterns, etc. It is mainly based on basic infrastructure of product and process flow, specialized software, experts and skilled workers to work at this specialized level. Continuing with the example of a manufacturing organization, workflow diagrams of product development, communication pattern with different departments during new product development, design diagrams of new product prototype, marketing departments input on prototype testing can be consolidated in this section.

\section{Conclusion}

The above discussion shows that the business model is an essential part of knowledge repository and is composed of knowledge related functions of an organization. These knowledge related functions are composed of value creating processes and knowledge is the primary source underlying value creation. The business model concept provides opportunities to organizations to achieve a sustainable position in the value creation chain. These organizations, being heterogeneous in activities and functions, may share one similarity with each other in the sense that they create value which can be shared with other organizations in a value chain.
These functions can be grouped into different layers of knowledge repository in terms of knowledge related functions. We also discussed that business models provide a framework of value creation processes and knowledge related functions to share the value created by each organization in a value chain. The value created is shared by all interacting partners, including the value creating organization. This is also the underlying assumption of the term 'open business models' by Chesbrough (2006). Therefore, we may assume that all business models may be 'open business models' in the sense if they create value among participating business actors and capture part of the value created within value chain. Since successful businesses undergo transformation processes whenever required, the concept of the knowledge repository may provide the opportunity to study the organizational transformation at an activity level which helps to understand the processes of value creation individually.

This paper may lead to further research of analyzing knowledge related functions at activity level within a single organization which will help to reveal the mechanism of value creation in the framework of business models in terms of knowledge management. It was also observed during the literature review for the concept of business models that so far no grounding theory of business model concepts, in terms of knowledge management, has been proposed in the academic literature. Therefore, this discussion may provide foundations to initiate extensive inductive empirical research in this domain. The current paper is an overview of a proposal to initiate a debate on the existence of a business model concepts in the domain of knowledge management. An attempt is required to "present the notion of business model in a systematic view by specifying relations among variables with the purpose of explaining and predicting the phenomena (Business model)" (Kerlinger, 1974). Business model concepts should be considered as real life phenomena which could have an adequate influence on the sustainability of firms and organizations in today's intense competitive environment. Therefore, there is a dire need to develop the grounding theory of business model concept due to its prime importance in coming years of fierce competition.

\section{References}

Afuah, A. "Business Models, A Strategic Management Approach”. $1^{\text {st }}$ edition. McGraw Hill Companies Inc. 2004.

Bannon, L. J. \& Kuutti, K. "Shifting Perspectives on Organizational Memory: From Storage to Active Remembering". Proceedings of 29th Hawaii International Conference on System Sciences, Hawaii IEEE. January 1996.

Bureau of Justice Assistance, US Dept of Justice. “Define: Function”. Glossary of Program Evaluation. http://www.ojp.usdoj.gov/BJA/evaluation/glossary/glossary_f.htm (accessed May 7, 2008).

Chesbrough, H. and Rosenbloom, R. S. "The role of the business model in capturing value from innovation: Evidence from Xerox Corporation's technology spin-off companies". Industrial and Corporate Change (2002) 11(3): 529-555. 
Chesbrough, H. “Open Business models: How to thrive in the new innovation landscape”. Boston: Harvard Business School Press, 2006.

Davenport, Thomas H and Prusak, L. “Working knowledge. How organizations manage what they know?" $2^{\text {nd }}$ Revised Edition, Harvard Business School Press. 2000.

Dingsøyr, T \& Røyrvik, E. “An Empirical study of an informal knowledge repository in a medium sized software consulting company". Proceedings of 25th International Conference on software Engineering (2003), 84-92.

Emery, James D. "Designing Firm Integrating Processes from the Knowledge-based View". Graduate Student Best Paper Award, Proceedings of Computational Analysis of Social and Organizational Systems (CASOS) Conference 2002.

Felin, T. and Herstely, Willaim S. "The Knowledge-Based View, Nested Heterogeneity, and new value creation: Philosophical Considerations on the Locus of Knowledge". Academy of Management Review 32(1), (2007) 195 - 218.

Gallupe, B. "Knowledge management systems: surveying the landscape". International Journal of Management Reviews 3(1), 2001.

GAO. US Govt. Accountability Office. "Define: Function”. BPR Glossary of Terms. http://www.gao.gov/special.pubs/bprag/bprgloss.htm (accessed May 7, 2008).

Gordijn, J \& Akkermans, H. "Value Based Requirements Engineering: Exploring Innovative e-Commerce Ideas". Requirements Engineering Journal, 8 (2002): 114-134.

Jones, G. R. and George, J. M. “Contemporary Management”. $2^{\text {nd }}$ edition. The McGraw Hill Companies Inc, .2000.

Kerlinger, F. "Foundations of Behavioural Research". New York: Holt Rienhart and Winston, Inc. 1974.

Lambert, S. "A Business Model Research Schema”. Proceedings of 19th Bled Conference 'e-Values'. Bled Slovenia, 2006.

Liebowitz, J. and Beckman, T. "Knowledge Organizations: What Every Manager Should Know”, CRC Press, 1998.

Linder, J. and Cantrell, S. "Changing business models: Surveying the Landscape". Accenture institute for strategic change, 2000.

Miller, George A. "Define: Function”. WordNet Cognitive Science Laboratory. Princeton University. http://wordnet.princeton.edu/perl/webwn?s=function\&sub=Search+WordNet\&o2=\&o0=1\&o7=\&o5=\&o1=1\&o6=\&o4=\&o3=\&h= (accessed May 7, 2008).

Morgan Madison \& Company. "Define: business function”. Glossary for professional. http://www.mgrush.com/content/view/70/33/\#businessfunction (accessed May 7, 2008).

Ostenwalder, A. Pigneur, Y. and Tucci, C. L. "Clarifying Business Models: Origins, Present, and Future of the Concept". Communications of AIS, 15, May 2005.

Österle, H. "Business in the information age: Heading for New Processes". Berlin: Springer-Verlag 1995.

Osterwalder, A. "The business model ontology, a proposition in a design science approach". Ph.D. diss., University of Lausanne, Switzerland, 2004.

Pateli, A. and Giaglis, G. "A research framework for analysing e- business models". European Journal of Information Systems 13: 302-314. 2004.

Polanyi, M. “The Tacit Dimension” Doubleday Publisher, 1966.

Porter, Michael E. "Strategy and the Internet". Harvard Business Review (March 2001): 63-78

Rowley, J. "Is higher education ready for knowledge management?" The international journal of Education Management 17(3), 325-333, 2000.

Samaddar, S. and Priestley, J. "Network Structure and Inter-organizational Knowledge Sharing Capability" Presented at SEDSI Regional Conference in Raleigh, NC. (February 2005): 22-24.

Sveiby, Karl-Erik. "A Knowledge-based Theory of the Firm To guide Strategy Formulation”. Journal of Intellectual Capital 2(4), 2001.

Tapscott, D. "Winning with the Enterprise 2.0". New Paradigm Learning Corporation 2006. http://204.15.36.164/media/Winning_with_the_Enterprise_2.0.pdf

Timmers, P. "Business Models for Electronic Markets”. Journal of Electronic Markets 8(3), 3-8, 1998.

Weill, P. and Vitale, M. R. "Place to space: Migrating to e-Business Models". Boston: Harvard Business School Press, 2001.

Zack, M. "Managing codified knowledge". MIT Sloan Management Review (1999): 45-58.

\section{About the Authors}

Rozeia Mustafa

Rozeia Mustafa is a PhD student at the Vienna University of Technology, working on the relationship of business models and knowledge management. She has a master in business administration from the National Textile College, Pakistan.

\section{Hannes Werthner}

Hannes Werthner is Professor for e-commerce at the Vienna University of Technology; previously at the Vienna University of Economics and the University of Trento, Italy. He holds a Master and Ph.D. from the Vienna University of Technology. He was visiting professor at several universities, published over 100 papers and 

VOLUME 8

books, and was a fellow from the Austrian Schrödinger foundation. His research activities cover e-commerce, Internet-based Information systems, Decision Support Systems, Simulation and Artificial Intelligence. 


\section{EDITORS}

Mary Kalantzis, University of Illinois, Urbana-Champaign, USA.

Bill Cope, University of Illinois, Urbana-Champaign, USA.

\section{EDITORIAL ADVISORY BOARD}

Verna Allee, Verna Allee Associates, California, USA.

Zainal Ariffin, Universiti Sains Malaysia, Penang, Malaysia.

Robert Brooks, Monash University, Melbourne, Australia.

Bruce Cronin, University of Greenwich, UK.

Rod Dilnutt, William Bethway and Associates, Melbourne, Australia.

Judith Ellis, Enterprise Knowledge, Melbourne, Australia.

Andrea Fried, Chemnitz University of Technology, Germany.

David Gurteen, Gurteen Knowledge, UK.

David Hakken, University of Indiana, Bloomington, Indiana, USA.

Sabine Hoffmann, Macquarie University, Australia.

Stavros loannides, Pantion University, Athens, Greece.

Margaret Jackson, RMIT University, Melbourne, Australia.

Paul James, RMIT University, Melbourne, Australia.

Leslie Johnson, University of Greenwich, UK.

Eleni Karantzola, University of the Aegean, Rhodes, Greece.

Gerasimos Kouzelis, University of Athens, Greece.

Krishan Kumar, University of Virginia, USA.

Martyn Laycock, University of Greenwich and managingtransitions.net, UK.

David Lyon, Queens University, Ontario, Canada.

Bill Martin, RMIT University, Melbourne, Australia.

Pumela Msweli-Mbanga, University of Kwazulu-Natal, South Africa.

Claudia Schmitz, Cenandu Learning Agency, Germany.

Kirpal Singh, Singapore Management University, Singapore.

Dave Snowden, Cynefin Centre for Organisational Complexity, UK.

Chryssi Vitsilakis-Soroniatis, University of the Aegean, Rhodes, Greece.

Please visit the Journal website at http://www.Management-Journal.com for further information about the Journal or to subscribe. 


\title{
THE UNIVERSITY PRESS JOURNALS
}

\author{
International Journal of the Arts in Society \\ Creates a space for dialogue on innovative theories and practices in the arts, and their inter-relationships with society. \\ ISSN: 1833-1866 \\ http://www.Arts-Journal.com
}

International Journal of the Book

Explores the past, present and future of books, publishing, libraries, information, literacy and learning in the information society. ISSN: 1447-9567

http://www.Book-Journal.com

Design Principles and Practices: An International Journal

Examines the meaning and purpose of 'design' while also speaking in grounded ways about the task of design and the use of designed artefacts and processes. ISSN: 1833-1874 http://www.Design-Journal.com

International Journal of Diversity in Organisations, Communities and Nations

Provides a forum for discussion and builds a body of knowledge on the forms and dynamics of difference and diversity. ISSN: $1447-9583$ http://www.Diversity-Journal.com

International Journal of Environmental, Cultural, Economic and Social Sustainability

Draws from the various fields and perspectives through which we can address fundamental questions of sustainability. ISSN: 1832-2077

http://www.Sustainability-Journal.com

Global Studies Journal

Maps and interprets new trends and patterns in globalization. ISSN 1835-4432 http://www.GlobalStudiesJournal.com

International Journal of the Humanities

Discusses the role of the humanities in contemplating the future and the human, in an era otherwise dominated by scientific, technical and economic rationalisms. ISSN: 1447-9559 http://www. Humanities-Journal.com

International Journal of the Inclusive Museum

Addresses the key question: How can the institution of the museum become more inclusive? ISSN 1835-2014 http://www.Museum-Journal.com

International Journal of Interdisciplinary Social Sciences

Discusses disciplinary and interdisciplinary approaches to knowledge creation within and across the various social sciences and between the social, natural and applied sciences.

ISSN: 1833-1882

http://www.Socialsciences-Journal.com

International Journal of Knowledge, Culture and Change Management

Creates a space for discussion of the nature and future of organisations, in all their forms and manifestations.

ISSN: $1447-9575$

http://www.Management-Journal.com

International Journal of Learning

Sets out to foster inquiry, invite dialogue and build a body of knowledge on the nature and future of learning.

ISSN: $1447-9540$

http://www.Learning-Journal.com

International Journal of Technology, Knowledge and Society

Focuses on a range of critically important themes in the various fields that address the complex and subtle relationships between technology, knowledge and society. ISSN: 1832-3669 http://www.Technology-Journal.com

Journal of the World Universities Forum

Explores the meaning and purpose of the academy in times of striking social transformation. ISSN 1835-2030

http://www.Universities-Journal.com

\author{
FOR SUBSCRIPTION INFORMATION, PLEASE CONTACT \\ subscriptions@commonground.com.au
}

